\title{
Üniversite Öğrencilerinde Duygusal Zekâ ile Okul Doyumu ilişkisinde Akademik Mükemmeliyetçilik ve Ertelemenin Sıralı Aracılığı
}

\author{
Begüm SATICI*
}

\begin{abstract}
Öz: Bu çalışmanın amacı duygusal zekâ ile okul doyumu ilişkisinde akademik mükemmeliyetçiliğin ve akademik ertelemenin sıralı aracılığını test etmektir. Çalışmanın katılımcılarını \%58.9'u kadın ve \%41.1'i erkek olmak üzere toplam 309 gönüllü üniversite öğrencisi meydana getirmektedir. Çalışmanın verileri Duygusal Zeka Özelliği Ölçeği-Kısa Formu, Akademik Mükemmeliyetçilik Ölçeği, Tuckman Erteleme Ölçeği ve Okul Doyumu Ölçeği ile elde edilmiştir. Çalışmanın verileri bootstrapping temelli sıralı çoklu aracılık modeli PROCESS ile test edilmiştir. Bulgular, akademik mükemmeliyetçilik ile akademik ertelemenin duygusal zekâ ve okul doyumu ilişkisinde sıralı aracılık yaptıklarını ortaya çıkarmıştır. Bu bağlamda düşünüldüğünde; duygusal zekânın artması öğrencilerin akademik mükemmeliyetçilik eğilimlerinin azalabileceği anlamına gelmektedir. Bununla birlikte akademik mükemmeliyetçilikteki azalma, akademik ertelemeyi de düşürerek okul doyumunun güçlenmesini sağlayabilecektir. Çalışmada test edilen modele yönelik bulgular ilgili alan yazına bağlı olarak tartışılmış ve eğitim bilimciler ile psikolojik danışmanlara yönelik doğurgular verilmiştir.
\end{abstract}

Anahtar Sözcükler: Okul Doyumu, Duygusal Zekâ, Akademik Mükemmeliyetçilik, Akademik Erteleme, Sıralı Aracilık Modeli

\section{Academic Perfectionism and Procrastination as Serial Mediators in the Relationship between Emotional Intelligence and School Satisfaction in University Students}

\begin{abstract}
This study aimed to identify the serial mediating roles of academic perfection and academic procrastination on the relationship between emotional intelligence and school satisfaction. The study participants comprised of 309 volunteer university students, of whom $58.9 \%$ were females and $41.1 \%$ were males. The data were gathered via Emotional Intelligence QuestionnaireShort Form, Academic Perfectionism Scale, Tuckman Procrastination Scale, and Satisfaction with Schooling Scale. A bootstrapping based serial multiple mediation model was tested via PROCESS. The findings indicated that academic perfection and academic procrastination act as serial mediators between emotional intelligence and school satisfaction, meaning that students with increased emotional intelligence have a lower tendency toward academic perfection. This, in turn, findings in a decrease in academic procrastination and an increase in school satisfaction. The study was discussed with the related literature and the implications were given to educational scientists and psychological counsellors.
\end{abstract}

Keywords: School Satisfaction, Emotional Intelligence, Academic Perfection, Academic Procrastination, Serial Mediating Model 
Eğitim hayatının genellikle son aşaması olarak görülen üniversite; öğrencilerin iş, aile ve sosyal yaşamlarının önemli bir belirleyicisi olabilmektedir. Başarılı ve nitelikli geçen üniversite eğitimi sonrasında bireyler yetişkin hayatına atıldıklarında sorumluluklarını yerine getirme konusunda kendilerini yeterli hissedebilirler. Aksi düşünüldüğünde, verimsiz bir üniversite hayatı sonrası bireyler mezun olduklarında kendi becerilerine ve eğitimlerine göre iş bulma ve mesleğini yapabilme konusunda bir takım sıkıntılar yaşayabilir, tabir yerindeyse sudan çıkmış balığa dönebilirler. Bu nedenle eğitimin başlangıç basamağı gibi son basamağı da bireylerin hayatlarında dönüm noktası gibidir ve bu dönüm noktasının sağlıklı bir şekilde üstesinden gelinmesi için öğrencilerin üniversite yaşamlarının kalitesinin arttırılmasına yönelik araştırmaların yapılmasına ihtiyaç vardır. Bu açıdan ele alındığında okul yaşamının kalitesine ilişkin öğrencilerin algılarını öğrenebilmek önemli görülmektedir (Argon ve Kösterelioğlu, 2009; Özdemir, 2012; Özdemir, Kılınç, Öğdem ve Er, 2013). Bu nedenle bu araştırmanın bağımlı değişkeni olarak okul doyumu kavramı ele alınacaktır.

Okul doyumu kavramı ilkokul, ortaokul ve lise düzeyindeki öğrencilerle çalışılmış olsa da üniversite öğrencilerinin okul doyumları ile ilgili oldukça az sayıda araştırmaya rastlanmıştır (Garcia-Molsosa, ColletSabé, Martori ve Montserrat, 2019; Thomas ve Galambos, 2004). Oysa üniversite öğrenimini yarıda bırakan öğrenci sayısı 2018 yılında bir önceki yıla göre yüzde 92,2 artarak 408 bini aşmıştır (Güçlü, 2019). Üniversite öğrencilerinin okul doyumlarının arttırılmasının okula devamlılı̆̆ı sağlamakla birlikte ailevi, mesleki ve sosyal açıdan yaşamlarında önemli bir fark yaratacă̆ ifade edilmektedir (Hammer, Grigsby ve Woods, 1998). Basitçe düşünülecek olursa okuldan doyum elde etmeyen bir üniversite öğrencisi okula daha az devam edecek, dolayısıyla derslerinde daha fazla başarılı olma şansını kaçırarak mezuniyetini bile geciktirebilecektir. Mezun olsa bile iş bulma olanaklarının zayıflayacağı ve bu durumun aile içinde de bir sorun teşkil edebileceği ön görülebilir. Dolayısıyla okul doyumunun olmaması üniversite öğrencilerinin iş dünyasına katkıda bulunma ihtimalini de düşüreceğinden ülke ekonomisi açısından da daha büyük sorunları beraberinde getirebilecektir. $\mathrm{Bu}$ açıdan ele alındı̆̆ında üniversite öğrencilerinin okul doyumlarına yönelik gerçekleştirilecek araştırmaların teorik ve pratik katkılarının önemli olduğu düşünülmektedir.

Okul doyumu bireyin okuldaki arkadaşları ve öğretmenleri ile ilişkileriyle birlikte eğitim süreci ve akademik deneyimlerini içeren okul performansına yönelik bilişsel değerlendirmelerini içermektedir (Suldo, Baterman ve Gelly, 2014). Okul hayatının kalitesine ilişkin öğrencilerin bilişsel ve öznel değerlendirmelerini ifade eden okul doyumu (Huebner, 1994) okula uyumun bir işareti olarak görülmekte (Baker, Dilly, Aupperlee ve Patil, 2003) ve öğrencilerin okula devam etmeleri açısından oldukça önemli bir kavram olarak karşımıza çıkmaktadır (Ainley, Foreman ve Sheret, 1991). Okul doyumu yüksek olan öğrencilerin daha az devamsızlık yaptıkları, derse vaktinde geldikleri, akademik başarılarının daha yüksek olduğu ve problemli davranışlar sergilemedikleri ortaya konmuştur (Firestone, Rosenblum ve Webb, 1987). Ayn zamanda okul doyumu öğrencilerin okulda gerçekleştirdikleri eğitsel ve sosyal faaliyetler ile birlikte okul hayatına katılımlarını artırarak iyi oluşlarına da katkı sağlayan bir unsur olarak görülmektedir (Karatzias, Power, Flemming, Lennan ve Swanson, 2002). Okul doyumu açısından önemli olan okul performansının yükselmesi için tek belirleyici faktörün bilişsel yetenekler olmadığı aynı zamanda duyguların sağlıklı bir şekilde yönetilmesinin de gerekli olduğu vurgulanmaktadır (Rego ve Fernandes, 2004). Benzer şekilde öğrencinin arkadaşları ve öğretmenleri ile ilişkisini düzenleyen kişilerarası iletişimin sağlıklı bir şekilde devam ettirilmesinde de duyguların yadsınamaz bir yeri vardır (Bar-On, 2006). Kısacası okul doyumu, eğitimsel uyum ve duygusal uyumun önemli bir göstergesi olarak değerlendirilir (Baker ve diğerleri, 2003). Böylelikle öz-farkındalık, kendini yönetme becerisi, sosyal farkındalık ve ilişki yönetimi olmak üzere çeşitli yeterlikleri kapsayan duygusal zekâ kavramı (Goleman, 1998) da okul doyumunun bileşenleri açısından gerekli bir faktör olarak karşımıza çıkmaktadır.

Duygusal zekâ duyguları anlama, düzenleme ve aktarabilme becerilerini (Matthews, Zeidner ve Roberts, 2004) gerektirmektedir. Duygusal zekâsı yüksek bireylerin iş, aile ve sosyal yaşantılarında daha az problem yaşadıkları, sosyal becerilerinin kuvvetli olduğu bilinmektedir (Goleman, 2006). Bu açıdan duygusal zekâya sahip bir öğrencinin hem arkadaşlarıyla hem de öğretmenleriyle olan iletişiminin daha sağlıklı olacağı söylenebilir. Bununla birlikte yeni öğrenme ortamında öğrenilen bilgilerin kalıcılığını sağlayan kendini düzenleme becerileriyle içsel motivasyonu da destekleyen duygusal zekâ (Dunn ve Griggs, 2000; Becker, 
McElvany ve Kortenbruck, 2010) öğrencilerin okul performansını arttırarak da okul doyumlarına katkı sağlayabilmektedir. Duygusal zekâya sahip öğrenciler içsel motivasyon kaynakları ile güdülendikleri için akademik zorluklarla karşılaşsalar bile kendi kendilerini memnun edebilmeyi ve zorlukların üstesinden gelebilmeyi başarabilmekte ve okul doyumlarının olumsuz etkilenmediği söylenmektedir (Salovey ve Mayer, 1990). Öte yandan duygusal zekâsı düşük ve sürekli dışsal kaynaklarla motive olan öğrencilerin akademik başarılarının ve okul doyumlarının olumsuz etkilendiği görülmektedir (Wolters, Shirley ve Pintrich, 1996). Dolayısıyla duygusal zekânın okul doyumunu artırabilecek bir faktör olduğu öngörülebilir. Bunun ötesinde duygusal zekâ ile okul doyumu arasında aracılık yapabilecek başka faktörlerin de araştırılması gerekmektedir.

Duygusal zekâ ile okul doyumu arasında akademik süreçlerle ilgili ele alınabilecek etkenlerden bir tanesi akademik mükemmeliyetçilik kavramıdır. En iyiyi gerçekleştirme arzusu olarak tanımlanan mükemmeliyetçilik (Flett, Hewitt ve Heisel, 2014) kişiye bağlı olarak olumlu (yüksek performans gösterme) ve olumsuz (aşırı stres, öz eleştiri, vb.) eğilimleri içermektedir (Hamachek, 1978). Ancak söz konusu akademik mükemmeliyetçilik olduğunda, akademik ortamda yapabileceği hatalar hakkında aşırı endişe duyma, kendinden gerçekleştiremeyeceği beklentilerde bulunma, başarma konusunda ebeveynlerin beklentileri, ebeveynlerden gelen eleştirilerle yüzleşememe ve akademik girişimlerinden sürekli şüphe duymayı içeren durumlar daha ağır basmaktadır (Frost, Marten, Lahart ve Rosenblate, 1990). Mükemmeliyetçi özellikler sergileyen öğrenciler "ya hep ya hiç" ya da "her koşulda başarmalıyım" gibi "-meli, -malı" şeklinde zorunluluk içeren bilişsel çarpıtmalarla kendilerine gerçekleştirilmesi zor standartlar belirlerler (Antony ve Swinson, 1998). Dolayısıyla akademik ortamdaki uyumsuz mükemmeliyetçi standartlar, öğrencilerde başarısızlık korkusuyla hataya az yer bırakır ve yoğun suçluluk duygusu (Rice, Ashby ve Slaney, 2007), kaygı, depresyon (Sherry, Hewitt, Flett ve Harvey, 2003) gibi olumsuz durumlarla sonuçlanabilir. Çünkü kendisine yüksek standartlar belirleyen öğrenciler, başarma hissini yaşayamadıkları için başarısızlık korkusu tarafından motive olmaktadırlar (Patch, 1984). Oysa duygusal zekâya sahip bireyler başarıya odaklanmakta ve kendi kendilerini kontrol edebilmektedirler (Goleman, 2006). Bu açıdan ele alındığında duygusal zekânın geliştirilmesinin akademik mükemmeliyetçilik düzeyini düşürebilecek bir faktör olabileceği öngörülebilir. Bununla birlikte uyumsuz akademik mükemmeliyetçilik gösteren öğrencilerin akademik başarılarının olumsuz etkilenmesinin (Ram, 2005) yanı sıra, başarı elde ettikleri zaman bile zaten ulaşmaları gereken bir nokta olduğunu düşündükleri için yeteri kadar haz elde edemedikleri görülmektedir (Patch, 1984). Bu durumun da okul performanslarından memnuniyetsizlikle birlikte okul doyumlarını olumsuz bir şekilde etkileyeceği düşünülebilir.

Her şeyi mükemmel yapma çabası aynı zamanda bireyin bir işe başlama ve tamamlamasında da karşısına güçlükler çıkarır (Steel, 2007). Bu nedenle akademik mükemmeliyetçiliğe sahip bireyler ödevleri, projeleri, sunumları yapma konusunda da erteleme davranışı sergileme eğilimindedirler (Closson ve Boutilier, 2017). Bu yüzden bu çalışmada akademik erteleme, akademik mükemmeliyetçilik ile birlikte duygusal zekâ ve okul doyumu arasında aracılık rolü olabileceği düşünülen bir diğer kavram olarak ele alınmıştır. Erteleme, bir eylemde bulunma niyetine rağmen eylemin gereksiz bir şekilde geciktirilmesi ve geciktirmenin kişiye rahatsızlık verecek bir düzeye gelmesi olarak tanımlanmaktadır (Steel, 2007). Bunun sebebi olarak da akademik mükemmeliyetçilikte olduğu gibi olumsuz eleştirilme ve yargılanmaya ilişkin kayg1, değerlendirilme endişesi gibi faktörlerle birlikte karar vermede zorluk, başarının sonuçlarından korkma, kontrol edilmeye karşı isyan, iddiasızlık, görev konusunda isteksiz olma ve kendini yetkin bulmama gibi bir takım etmenler ve mantık dışı inançlar görülmektedir (Solomon ve Rothblum, 1984). Üniversite öğrencileriyle gerçekleştirilen bir çalışmada sınıf düzeyi ilerledikçe ertelemenin de daha çok yapıldığı gözlenmiştir (Semb, Glick ve Spencer, 1979). Öte yandan öğrencilerin dönem başında en çok çaba harcadıkları ve kaygı verici olarak algıladıkları derslerdeki akademik görevler için erteleme ihtimallerinin daha yüksek olduğu görülmektedir (Ferrari ve Scher, 2000). Akademik erteleme düzeyi yüksek olan bireylerde düşük benlik saygisı (Solomon ve Rothblum, 1984), anksiyete ve depresyon (Constantin, English ve Mazmanian, 2018) gibi sorunlar ortaya konmuştur. Oysa duygusal zekâya sahip bireyler; güçlükle karşılaştıkları zaman bu durumu başarılı bir şekilde yönetebilir, baskı altında olsalar bile sakin kalabilirler, zorlu şartlarda bile olumlu bakış açısını yakalayabilir ve bir işi yapmak için kendilerini motive edebilirler (Stein, 2009). Dolayısıyla öğrencilerde duygusal zekânın geliştirilmesinin akademik erteleme davranışlarını azaltmada da etkili olabileceği 
düşünülebilir. Akademik erteleme aynı zamanda düşük akademik başarı ve dersi bırakma ile ilişkili olarak okul performansına zarar vererek (Semb ve diğerleri, 1979) okul doyumunu da olumsuz yönde etkileyecek bir faktördür. Sonuç olarak duygusal zekânın geliştirilmesi ile ilişkili olarak akademik mükemmeliyetçilik ve akademik erteleme düzeylerinin düşürülmesinin öğrencilerin okul doyumlarına olumlu katkısı olacağı öngörülmektedir. Dolayısıyla alan yazında belirtilen teorik açıklamalar ve önceki araştırma sonuçlarından yola çıkarak aşağıdaki araştırma sorularına cevap aranmıştır:

1. Duygusal zekâ ile okul doyumu arasında akademik mükemmeliyetçiliğin aracılık rolü var mıdır?

2. Duygusal zekâ ile okul doyumu arasında akademik ertelemenin aracılık rolü var mıdır?

3. Akademik mükemmeliyetçilik ve akademik erteleme, duygusal zekâ ile okul doyumu ilişkisinde sıralı aracilık yapmakta mıdır?

\section{Yöntem}

Üniversite öğrencilerinde duygusal zekâ ile okul doyumu ilişkisinde akademik mükemmeliyetçilik ve akademik ertelemenin sıralı aracılık rollerini inceleyen bu araştırma, ilişkisel tarama modeli türündedir. Bu tür tarama modellerinde birden fazla değişken arasında ilişkilerin var olup olmadığının tespit edilmesi amaçlanmaktadır (Fraenkel ve Wallen, 2011).

\section{Çalışma Grubu}

Bu çalışma 182'si (\%58.9) kadın ve 127'si (\%41.1) erkek olmak üzere toplam 309 (Yaşort = 19.37, ss = 1.49) üniversite öğrencisinin katılımı ile gerçekleştirilmiştir. Artvin Çoruh Üniversitesi'nde öğrenim gören katılımcıların günlük ortalama ders çalışma saatleri $1.24^{\prime}$ dür $(\mathrm{ss}=.98)$. Sınıf düzeyleri açısından bakıldığında; 121'i (\%39.2) birinci sınıf, 90'ı (\%29.1) ikinci sınıf, 54'ü (\%17.5) üçüncü sınıf ve 44'ü (\%14.2) dördüncü sınıfta öğrenim görmektedir.

\section{Araştırmada İzlenen Etik Kurallar}

Bu araştırma Helsinki Deklerasyon'u bağlamında ele alınmıştır. Bu doğrultuda çalışmadaki veri araçları yalnızca gönüllü katılımcılara dağıtılmıştır. Bununla birlikte çalışmada yer alan tüm katılımcılardan bilgilendirilmiş onam sağlanmıştır. Ek olarak katılımcılara, veri toplama esnasından diledikleri zaman geri çekilebilecekleri bilgisi verilmiştir.

\section{Veri Toplama Araçları}

Duygusal zeka özelliği ölçeği - kısa formu. Öğrencilerin duygusal zekâ düzeylerini belirleyebilmek amacıyla kullanılan ölçek Petrides ve Furnham $(2000,2001)$ tarafından geliştirilmiştir. 7'li likert tipi derecelendirmeye sahip olan ölçekten alınabilecek olası yüksek puanlar duygusal zekâ düzeyinin de yükseldiğini ifade etmektedir. Ölçeğin Türkçe formunun psikometrik özellikleri Deniz, Özer ve Işık (2013) tarafından incelenmiştir. Türkçe formu 16 madde (örn. "Genellikle, yeni çevreye uyum sağlama yeteneğim vardır.") olan ölçeğin uyarlama çalışmasının doğrulayıcı faktör analizi sonucunda geçerli $\left(\chi^{2} / \mathrm{sd}=2.46, \mathrm{GFI}=\right.$ .95 , AGFI $=.92, \mathrm{CFI}=.91$, RMSEA $=.056$ ve SRMR $=.060)$ ve iç tutarlık analizi sonucunda $(\alpha=.81)$ güvenilir olduğu rapor edilmiştir. Bu çalışma kapsamında da ölçeğin kabul edilebilir güvenirlik katsayısına $(\alpha=.78)$ sahip olduğu anlaşılmıştır.

Akademik mükemmeliyetçilik ölçeği. Öğrencilerin akademik mükemmeliyetçilik düzeylerini belirleyebilmek amacıyla kullanılan ölçek Odacı, Kalkan ve Çikrıkci (2017) tarafından geliştirilmiştir. 13 madde (örn. "Sınavlarda başarılı olamayacağım diye sürekli endişelenirim.") ve 5'li likert tipi derecelendirmeye sahip olan ölçekten alınabilecek olası yüksek puanlar akademik mükemmeliyetçilik düzeyinin de yükseldiğini ifade etmektedir. Ölçeğin geliştirme çalışmasının doğrulayıcı faktör analizi sonucunda geçerli $\left(\chi^{2} / \mathrm{sd}=2.36, \mathrm{GFI}=.94, \mathrm{AGFI}=.91, \mathrm{CFI}=.91, \mathrm{RMSEA}=.06\right.$ ve SRMR $\left.=.05\right)$ ve iç tutarlık analizi sonucunda $(\alpha=.82)$ güvenilir olduğu rapor edilmiştir. Bu çalışma kapsamında da ölçeğin kabul edilebilir güvenirlik katsayısına $(\alpha=.81)$ sahip olduğu anlaşılmıştır. 
Tuckman erteleme ölçeği. Öğrencilerin akademik erteleme düzeylerini belirleyebilmek amaciyla kullanılan ölçek Tuckman (1991) tarafından geliştirilmiştir. 5'li likert tipi derecelendirmeye sahip olan ölçekten alınabilecek olası yüksek puanlar akademik erteleme düzeyinin de yükseldiğini ifade etmektedir. Ölçeğin Türkçe formunun psikometrik özellikleri Uzun-Özer, Saçkes ve Tuckman (2013) tarafından incelenmiştir. Türkçe formu 14 madde (örn. "Çalışma alışkanlıklarımı geliştirmeyi ertelerim.") olan ölçeğin uyarlama çalışmasının doğrulayıcı faktör analizi sonucunda geçerli $\left(\chi^{2} / \mathrm{sd}=3.08, \mathrm{GFI}=.95, \mathrm{NNFI}=.98, \mathrm{CFI}=.98\right.$ ve RMSEA $=.058)$ ve iç tutarlık analizi sonucunda $(\alpha=.90)$ güvenilir olduğu rapor edilmiştir. Bu çalışma kapsamında da ölçeğin kabul edilebilir güvenirlik katsayısına $(\alpha=.87)$ sahip olduğu anlaşılmıştır.

Okul doyumu ölçeği. Öğrencilerin okul doyumu düzeylerini belirleyebilmek amacıyla kullanılan ölçek Randolph, Kangas ve Ruokamo (2009) tarafından geliştirilmiştir. 5'li likert tipi derecelendirmeye sahip olan ölçekten alınabilecek olası yüksek puanlar okul doyumu düzeyinin de yükseldiğini ifade etmektedir. Ölçeğin Türkçe formunun psikometrik özellikleri Telef (2014) tarafından incelenmiştir. Türkçe formu 6 madde (örn. "Okuldaki günlerim güzeldir.") olan ölçeğin uyarlama çalışmasının doğrulayıcı faktör analizi sonucunda geçerli $(\mathrm{GFI}=.98, \mathrm{NFI}=.99, \mathrm{CFI}=.99, \mathrm{IFI}=.99$ ve $\mathrm{RMSEA}=.06)$ ve iç tutarlık analizi sonucunda $(\alpha=.89)$ güvenilir olduğu rapor edilmiştir. Bu çalışma kapsamında da ölçeğin kabul edilebilir güvenirlik katsayısına $(\alpha=.71)$ sahip olduğu anlaşılmıştır.

\section{Verilerin Analizi}

Duygusal zekâ ile okul doyumu arasında akademik mükemmeliyetçilik ve akademik ertelemenin sıralı çoklu aracılığını test etmek için Hayes (2018) tarafından SPSS makrosu olarak geliştirilen PROCESS v3.2 içerisindeki Model 6 kullanılmıştır. Hayes ve meslektaşları tarafından üzerinde sıkça çalışılan ve gün geçtikçe geliştirilen makrolar aracılı̆̆ıyla regresyon temelli bootstrapping tekniğine dayalı karmaşık modelleri tek bir analiz sonucunda birden fazla parametreyi içeren bulgular sağlamaktadır. Bu çalışma kapsamında gerçekleştirilen 10,000 bootstrap örneklemi ile ortaya bootstrap katsayısı çıkartılmış ve buna bağlı olarak \%95 güven aralıkları oluşturulmuştur. Bu analizlerde sonuçların anlamlı olarak kabul edilebilmesi için oluşan güven aralıklarının alt ve üst sınırlarının sıfırı kapsamaması gerekmektedir (Preacher ve Hayes, 2008). Alt ve üst limitler sıfırı içermediğinde incelenen doğrudan ve dolaylı etkinin anlamlı olduğu sonucuna varılmaktadır.

Sıralı çoklu aracılıkta bağımsız değişken olan duygusal zekânın $(X)$ bağımlı değişken olan okul doyumu $(Y)$ üzerindeki doğrudan ve dolaylı etkilerini incelerken aynı zamanda ilk aracı olan akademik mükemmeliyetçiliğin $\left(M_{1}\right)$ ikinci aracı olan akademik erteleme $\left(M_{2}\right)$ üzerinden de okul doyumuna olan etkisi ele alınabilmektedir. Dolayısıyla " $X \rightarrow M_{1} \rightarrow Y$ ", " $X \rightarrow M_{2} \rightarrow Y$ " ve " $X \rightarrow M_{1} \rightarrow M_{2} \rightarrow Y$ " olacak şekilde iç içe geçmiş üç ayrı aracılık modelini tek bir analizde test edebilmektedir. Başka bir ifade sıralı çoklu aracılık modelinde tek bir seferde; akademik mükemmeliyetçiliğin duygusal zekâ ile okul doyumu ilişkisindeki aracılık rolü incelenmekte, bununla birlikte akademik ertelemenin de duygusal zekâ ile okul doyumu ilişkisindeki aracılık rolü ele alınmaktadır. Bununla birlikte aynı modelde; duygusal zekânın okul doyumunu yordamasında sıralı bir şekilde akademik mükemmeliyetçilik ve akademik ertelemenin aracılık rollerinin olup olmadığ test edilmektedir. Aracılık modeli öncesinde ön analizler olarak değişkenlere ait ortalama, standart sapma, çarpıklık ve basıklık katsayıları incelenmiştir. Bununla birlikte değişkenler arası ilişkiler Pearson korelasyon katsayısı ile ele alınmıştır.

\section{Bulgular}

\section{Ön Analizler}

Çalışmada yer alan değişkenlere yönelik betimsel istatistikler ile korelasyon katsayıları Tablo 1'de görülmektedir.

Tablo I

Değişkenlere ait ön analiz sonuçları

\begin{tabular}{lcccc}
\hline Değişken & 1 & 2 & 3 & 4 \\
\hline 1. Okul doyumu & - & &
\end{tabular}




\begin{tabular}{lcccc} 
2. Duygusal zekâ & $.58^{* *}$ & - & & \\
3. Akademik mükemmeliyetçilik & $-.47^{* *}$ & $-.35^{* *}$ & - & - \\
4. Akademik erteleme & $.50^{* *}$ & $-.46^{* *}$ & $32^{* *}$ & 41.73 \\
\hline Ortalama & 21.97 & 90.94 & 36.08 & 9.89 \\
Standart sapma & 3.75 & 14.77 & 8.42 & .13 \\
Çarpıklık & -.57 & .14 & .12 & -.41 \\
Basıklık & .91 & -.24 & .11 & \\
\hline
\end{tabular}

** $p<.001$

Tablo 1'den anlaşılacağ göstermektedir $(r=.58, p<.001)$. Bunun aksine okul doyumu akademik mükemmeliyetçilik $(r=-.47, p<.001)$ ve akademik erteleme $(r=-.50, p<.001)$ ile ise negatif yönde anlamlı ilişkiler göstermektedir. Benzer şekilde duygusal zekâ ile akademik mükemmeliyetçilik $(r=-.35, p<.001)$ ve akademik erteleme $(r=-.46, p<.001)$ arasında da negatif yönde anlamlı ilişkiler belirlenmiştir. Son olarak akademik mükemmeliyetçilik ve akademik erteleme ise birbirleriyle pozitif yönde anlamlı ilişkilidir $(r=.32, p<.001)$.

\section{Aracilık Analizleri}

Duygusal zekâ ve okul doyumu arasında akademik mükemmeliyetçilik ve akademik ertelemenin sıralı çoklu aracılığ 1 bootstrapping temelli PROCESS makrosu ile analiz edilmiştir. Bu analizde duygusal zekânın $(X)$ doğrudan okul doyumunu $(Y)$ doğrudan ve dolaylı etkilemesine yönelik sonuçlar yer almaktadır (Şekil 1).
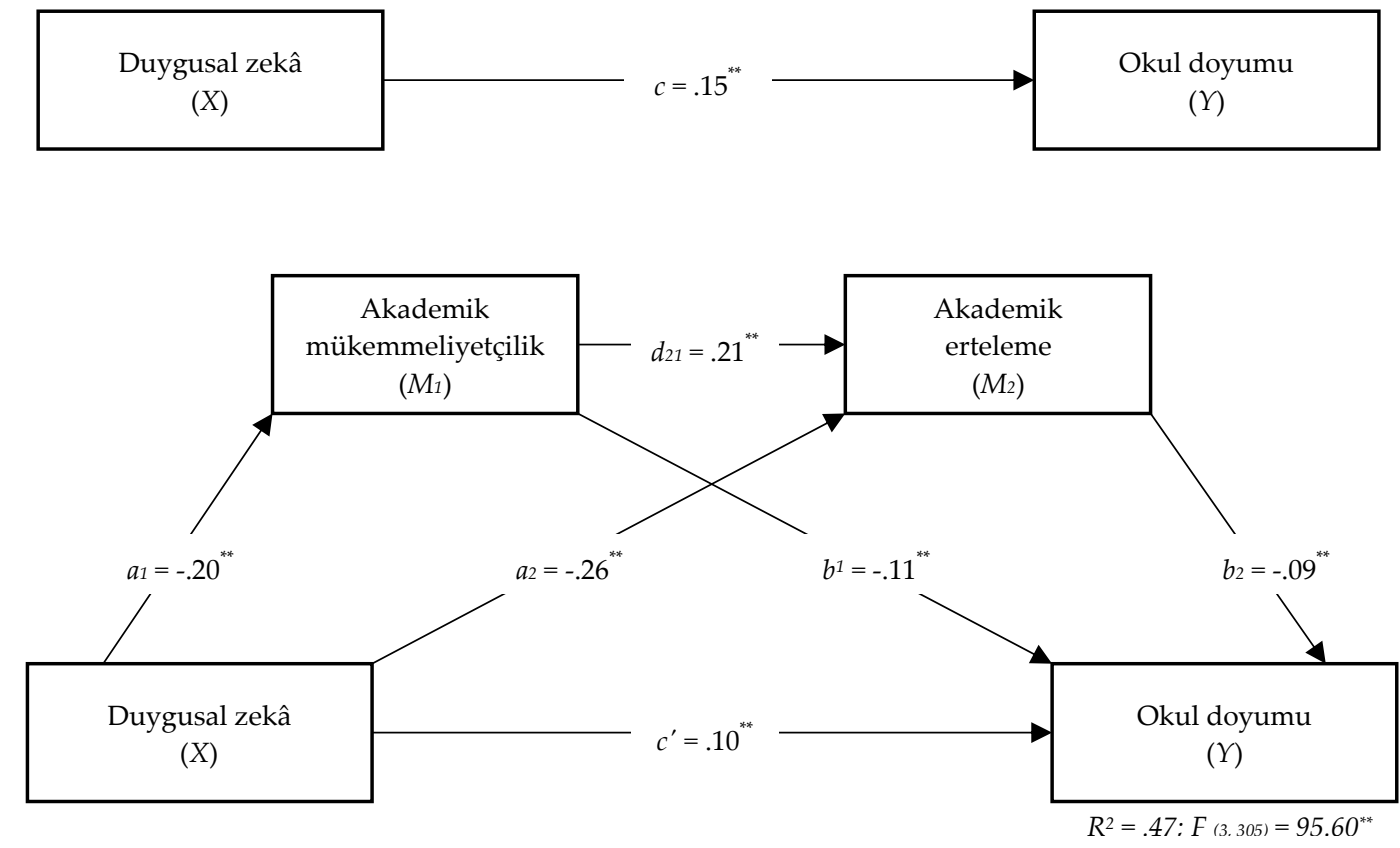

Şekil 1. Sıralı aracilık sonuçları, ${ }^{* *} p<.001$

Şekil 1'den görüleceği üzere, duygusal zekâ aracılar olmaksızın okul doyumunu doğrudan pozitif yordamaktadır $(c=.15, p<.001)$. Sıralı çoklu aracılık model incelendiğinde; duygusal zekânın aracılığı modele dâhil olduğunda okul doyumunu $\left(c^{\prime}=.10, p<.001\right)$ yordamasına yönelik katsayının düştüğü, ancak yine de anlamlı olduğu görülmektedir. Dolayısıyla modelde kısmi aracılığın söz konusu olduğu anlaşılmaktadır. Bununla birlikte duygusal zekâ hem akademik mükemmeliyetçiliği $\left(a_{1}=-.20, p<.001\right)$ hem de akademik ertelemeyi $\left(a_{2}=-.26, p<.001\right)$ doğrudan negatif yönde yordamaktadır. Ayrıca akademik mükemmeliyetçilik $\left(b_{1}=-.11, p<.001\right)$ ve akademik ertelemenin $\left(b_{2}=-.09, p<.001\right)$ de okul doyumunu negatif yönde yordadı $\breve{1} 1$ belirlenmiş̧ir. Bunlara ek olarak, okul doyumunu yordamasına yönelik kurulan aracılık modelinin anlamlı olduğu $[F(3,305)=95.60, p<.001]$ ve üç değişkenin okul doyumu toplam varyansının \%47'sini açıkladığı da saptanmıştır. Dolayısıyla sıralı çoklu aracılık modeli sonucunda; duygusal zekâ ile okul doyumu arasında akademik mükemmeliyetçiliğin aracı rolünün olduğu, bununla birlikte akademik ertelemenin de duygusal zekâ ile okul doyumu arasında aracılık yaptığı belirlenmiştir. Ek olarak, bu sıralı aracılık modeli sonucuna 
göre duygusal zekâ düzeyinin artması akademik mükemmeliyetçilik düzeyinin düşmesine, akademik mükemmeliyetçilik düzeyinin düşmesi de aynı zamanda akademik erteleme düzeyinin düşmesine ve bu düşüşlerin sonucu olarak okul doyumu düzeyinin artabileceği söylenebilir.

Modeldeki dolaylı yolların anlamlı olup olmadığına yönelik gerçekleştirilen analiz sonucundaki bootstrapping katsayı ile \%95 güven aralıkları alt ve üst limitleri Tablo 2' de yer almaktadır.

Tablo II

Sıralı çoklu aracılı̆̆a ait bootstrapping sonuçları

\begin{tabular}{|c|c|c|c|c|c|c|}
\hline Etki & Bootstrap Katsayısı a & Standart Hata & $t$ & $p$ & Alt limit $b$ & Üst limit $b$ \\
\hline Toplam etki & .152 & .011 & 13.08 & $<.001$ & .129 & .174 \\
\hline Doğrudan etki & .102 & .012 & 8.40 & $<.001$ & .078 & .126 \\
\hline Toplam dolaylı etki & .049 & .008 & & & .034 & .067 \\
\hline Dolaylı etki $\left(X \rightarrow M_{1} \rightarrow Y\right)$ & .022 & .006 & & & .012 & .036 \\
\hline Dolaylı etki $\left(X \rightarrow \rightarrow M_{2} \rightarrow Y\right)$ & .024 & .006 & & & .013 & .036 \\
\hline Dolaylı etki $\left(X \rightarrow M_{1} \rightarrow M_{2} \rightarrow Y\right)$ & .004 & .001 & & & .002 & .007 \\
\hline
\end{tabular}

a 10,000 bootstrap örneklemine dayanmaktadır. ${ }^{\mathrm{b}} \% 95$ Güven Aralıkları (GA)

Tablo 2'den görüleceği üzere modelde üç ayrı dolaylı etki söz konusudur. İlk dolaylı etkide; duygusal zekânın $(X)$ akademik mükemmeliyetçilik $\left(M_{1}\right)$ aracılı̆̆ıyla da okul doyumunu $(Y)$ anlamlı etkilediği görülmüştür, (bootstrap = .022, \%95 GA = .012, .036). İkinci olarak, duygusal zekânın akademik erteleme $\left(M_{2}\right)$ üzerinden okul doyumunu yordadığı dolaylı etkinin de anlamlı olduğu belirlenmiştir (bootstrap = .024, \%95 $\mathrm{GA}=.013$, .036). Son olarak duygusal zekânın akademik mükemmeliyetçilik ve akademik erteleme üzerinden sıralı bir şekilde okul doyumunu anlamlı bir şekilde etkilediği anlaşılmaktadır (bootstrap $=.004$, \%95 GA = $.002, .007)$.

\section{Sonuç ve Tartışma}

Bu çalışmada üniversite öğrencilerinde duygusal zekâ ile okul doyumu arasındaki ilişkide akademik mükemmeliyetçilik ve akademik ertelemenin sıralı aracılık rollerinin incelenmesi amaçlanmıştır. Bu doğrultuda gerçekleştirilen analiz sonuçlarına göre akademik mükemmeliyetçiliğin ve akademik ertelemenin bu iki değişken arasında kısmi aracılık yaptıkları ortaya konmuştur. Başka bir ifadeyle, öğrencilerin duygusal zekâlarının yükselmesi onların akademik mükemmeliyetçilik ve akademik erteleme düzeylerinin azalmasına ve bu dolaylı etki ile de okul doyumlarının artmasına neden olabileceği ortaya konmuştur. Bununla birlikte duygusal zekânın yükselmesi ile doğrudan da okul doyumunun artabileceği belirlenmiştir.

Bu çalışmanın ilk araştırma sorusunun yanıtı olarak duygusal zekâ ile okul doyumu arasında akademik mükemmeliyetçiliğin aracılık rolü ortaya konmuştur. Bu araştırmadan elde edilen sonuçlara göre duygusal zekânın akademik mükemmeliyetçiliği negatif yönde yordadığı bununla birlikte akademik mükemmeliyetçiliğin de okul doyumunu negatif yönde yordadığı belirlenmiştir. Alan yazın incelendiğinde duygusal zekâ ve akademik mükemmeliyetçilik ile ilgili doğrudan sonuçlara rastlanmasa da genel olarak mükemmeliyetçilik kavramına ilişkin benzer sonuçlar olduğu görülmektedir (Abdollahi ve Abu Talib, 2015; Gong, Fletcher ve Paulson, 2017; Smith, Saklofske ve Yan, 2015). Duygusal zekâ düzeyinin yükselmesi ile bilişsel çarpıtmaların azaldığı görülmektedir (Kamae ve Weisani, 2014; Petrides, Gómez ve Pérez-González, 2017). Akademik mükemmeliyetçilik söz konusu olduğunda da ulaşılması zor standartlar belirlemek ve sürekli buna ulaşmaya çalışmak mantıksal açıdan da ulaşılması mümkün olmayan bir durum olarak nitelendirilebilir. Dolayısıyla duygusal zekânın mükemmeliyetçiliği negatif yönde yordaması akla yatkın bir sonuç olarak karşımıza çıkmaktadır. Öte yandan akademik mükemmeliyetçilikte bireyler elde ettikleri başarılardan tatmin olamamakta, dolayısıyla okul performanslarını da olumsuz yönde değerlendirmektedirler (Frost ve diğerleri, 1990). Bununla birlikte akademik olarak en iyiye ulaşma çabası gösteren bireylerin sosyal ortamlardan ve arkadaşlarından da uzaklaşabileceği ya da düşük notlar aldıklarında öğretmenlerini de suçlayabilecekleri düşünülebilir. Tüm bunlar göz önünde bulundurulduğunda akademik mükemmeliyetçiliğin arkadaşlar ve öğretmenlerle ilişkiler ile okul performansına yönelik algıyı da kapsayan okul doyumunu olumsuz bir şekilde etkilediği değerlendirilebilir. Alan yazın incelendiğinde 
akademik mükemmeliyetçiliğin okul doyumunu negatif yönde yordadığına ilişkin sonuçlar da araştırmanın bu bulgusunu destekler niteliktedir (Gaudreau, Franche ve Gareau, 2016; Rice, Richardson ve Ray, 2016).

Bu çalışmanın ikinci araştırma sorusu duygusal zekâ ile okul doyumu arasında akademik ertelemenin aracılık rolü olup olmadığıdır. Araştırmanın bulguları doğrultusunda duygusal zekânın akademik ertelemeyi ve akademik ertelemenin de okul doyumunu negatif yönde yordadığı görülmektedir. Bu bulgu alan yazındaki araştırmalar tarafından da desteklenmektedir (Adesokan ve Eni-Olorunda, 2015; Deniz, Traş ve Aydoğan, 2009). Duygusal zekâya sahip bireylerin kendilerini motive etmek için yeterli öz-kontrol becerilerine sahip olduğu, zor durumlarda vazgeçmek yerine bu durumların üstesinden gelebildikleri ve olaylara olumlu açıdan yaklaştıkları (Stein, 2009) düşünüldüğünde akademik sorumluluklarını ertelemek yerine zamanında ve planlı bir şekilde gerçekleştirebilecekleri ve endişeye kapılmadan üstesinden gelebilecekleri düşünülebilir. Dolayısıyla duygusal zekâ düzeyinin düşmesi, bireylerde akademik ertelemeye daha çok sebep olabilmektedir. Dahası bireylerin akademik ertelemeleri arttıkça görevleri yerine getirmede isteksizlik ve sorumluluktan kaçma söz konusu olabileceği için, arkadaş ve öğretmenleri ile de ilişkilerinden sorunlar yaşayabilecek, akademik başarıları düşebilecek dolayısıyla okuldan daha az doyum elde edebileceklerdir. Araştırmanın akademik ertelemenin okul doyumunu negatif yönde yordadığına ilişkin bu bulgusu, alan yazındaki araştırmalar ile de desteklenmektedir (Balk1s, 2013; Chow, 2011; Duru ve Balkıs, 2017).

Çalışmanın son araştırma sorusunda duygusal zekâ ile okul doyumu arasında akademik mükemmeliyetçilik ve akademik ertelemenin sıralı aracılık rolü ele alınmıştır. Alan yazın incelendiğinde duygusal zekânın okul doyumunu pozitif yönde yordadığı görülmektedir (Varaşteanu ve Iftime, 2013). Duygusal zekâ ile okul doyumu arasında aracılık eden faktörler incelendiğinde akademik mükemmeliyetçilik ve akademik ertelemenin sıralı aracılık yapması bu araştırmanın sonuçları ile de doğrulanmıştır. Duygusal zekâ düzeyinin yükselmesi bireylerin başarma yönünde güdülenmelerine de olanak tanımaktadır (Goleman, 2006). Başarıya odaklanan bireylerin de ulaştıkları her amaçtan sonra motive olabilecekleri, yüksek standartlar aramadan mükemmeliyetçilikten uzaklaşabilecekleri düşünülebilir. Fakat duygusal zekâ düzeyi düşük olan bireylerin daha yüksek standartlar belirleyerek elde ettikleri başarılardan memnun olmaması, bu başarılarla motive olamamalarına ve daha iyisini yapabilmek için de kendilerini güdüleyememelerine dolayısıyla sürekli bir ertelemeye sebep olabilmektedir. Bir başka açıdan ele alındığında ise duygusal zekâ düzeyinin yükselmesinin bireyde mantık dışı inançların azalmasını sağladığı bilinmektedir (Kartol, 2013; Keser ve Traş, 2019; Petrides ve diğerleri, 2017). Oysa akademik mükemmeliyetçi özellikler gösteren bireylerin elde ettikleri normal başarılardan memnun olmadıkları ve değersizleştirdikleri, ancak üst düzey başarılardan tatmin oldukları ya da tamamen başarısızlıkla motive oldukları göz önüne alındığında (Patch, 1984) "ya hep ya hiç" şeklindeki mantık dışı inançlara sahip oldukları görülmektedir. Benzer şekilde sürekli kendilerine üst düzey standartlar belirleyerek "yap-malıyım, başar-malıyım" gibi yine mantık dışı inançları bulunmaktadırlar (Antony ve Swinson, 1998; Berber Çelik ve Odacı, 2015; Kağan, 2009). Dolayısıyla duygusal zekâ düzeyi düştükçe bireylerin bu gibi mantık dışı inançlara kapılarak akademik anlamda da mükemmeliyetçi bir tutum sergiledikleri söylenebilir. Bununla birlikte "ya hep ya hiç" diye düşünen bir kimsenin kendisine belirleyeceği ulaşılması güç hedefler, onu motive edemeyeceğinden dolayı akademik olarak ertelemesine de sebep olabilecektir. Çünkü kişi, kendisine ulaşamayacağı hedefler koyduğunun bir nevi farkındadır ve başaramamaktansa hiç başlamamayı tercih edebilmektedir. Sonuç olarak duygusal zekâ düzeyinin düşük olması akademik mükemmeliyetçiliğin ve sonrasında akademik ertelemenin artmasına neden olabileceği görülmektedir. Bununla birlikte bu durumların; bireylerin akademik sorumluluklarını yerine getirmemesine, sürekli sıkıntı ve kaygı duymasına, arkadaşları ve öğretmenleri ile ilişkilerinin bozulmasına ve dolayısıyla okul doyumunun azalmasına yol açabileceğini akla getirmektedir.

Çalışmanın bazı sınırlılıklarından bahsetmek mümkündür. Bunlar; öz-bildirime dayalı ölçme araçlarının kullanımı, verilerin genellenebilirliği ve doğrusal etkinin belirtilmesi olarak ifade edilebilir. Bu bakımdan sonraki çalışmalarda öz-bildirime dayalı ölçme araçlarının yanı sıra çalışmanın değişkenlerini ölçebilecek ve daha kapsamlı sonuçlar ortaya çıkartabilecek farklı tekniklerin de dâhil edilebilmesi önerilmektedir. Bununla birlikte bu çalışma küçük ölçekli bir devlet üniversitesinde öğrenim gören öğrencilerin katılımıyla gerçekleştirilmiştir. Dolayısıyla sonraki çalışmalarda farklı bölgelerden farklı büyüklükteki üniversitelerin 
öğrencilerinin katılımları sağlanarak araştırma sonuçlarının genellenebilirliği artırılabilir. Ayrıca bu çalışmada güncel bir teknik olan ve istatistiki olarak neden-sonuç bağını ortaya çıkarabilen bootstrapping tekniği kullanılmış olsa da verilerin kesitsel (cross-sectional) olmasından kaynaklı değişkenler arası yönler tam bir kesinlik ifade etmeyebilir. Bu bakımdan değişkenler arası bağlantının yönüne dair tam bir nedensellik ortaya çıkartabilmek için de sonraki çalışmalarda boylamsal ve deneysel desenlerin kullanılması önerilmektedir.

Bu sınırlıklarla birlikte çalışmanın akademisyenlere/eğitimcilere ve psikolojik danışmanlara yönelik doğurgularından da bahsetmek gerekmektedir. Okul doyumunun akademik başarının artması ve okul terkinin azaltılmasında önemli bir faktör olduğu anlaşılmaktadır. Bu bakımdan hem bireysel hem de toplumsal bir kazanç sağlayıcı olan okul doyumunun artırılmasına yönelik çalışmaların gerçekleştirilmesi önemli hale gelmiştir. Dolayısıyla akademisyenlerin okul doyumunu güçlendiren ve zayıflatan değişkenlerin neler olduğunu ortaya koymaları gerekmektedir. Her ne kadar daha önceki çalışmalar değişkenlerin ikili ilişkilerini ortaya koymuş olsalar da bu çalışmayla duygusal zekâ $\rightarrow$ akademik mükemmeliyetçilik $\rightarrow$ akademik erteleme $\rightarrow$ okul doyumu bağlantısının modellenmesinin alan yazına katkı sağlayıcı olduğu düşünülmektedir. Bununla birlikte akademisyenler farklı değişkenleri kullanarak yine okul doyumunu güçlendirmeye yönelik modeller kurarak hem teorik hem de pratik fayda sağlayabilirler. Ek olarak psikolojik danışmanların da bu çalışmanın sonuçlarından faydalanabilecekleri düşünülmektedir. Çalışmada yer alan duygusal zekânın geliştirilebilir; akademik mükemmeliyetçilik ve akademik ertelemenin de azaltılabilir bir değişken olduğu daha önceki araştırmalarda ortaya konmuştur. Buradan yola çıkarak psikolojik danışmanlara okul doyumu üzerinde anlamlı bir etkiye sahip olan duygusal zekâ, akademik mükemmeliyetçilik ve akademik ertelemeye yönelik grupla psikolojik danışma çalışmaları yapmaları önerilmektedir. Sonuç olarak öğrencilerin duygusal zekâ düzeyleri artabilecek ve böylece akademik mükemmeliyetçilik ile akademik erteleme düzeyleri azalarak okuldan doyum elde etmeleri yükselebilecektir.

\section{Yazar(lar)1n Beyanı}

Araştırmacıların katkı oranı beyanı: Çalışmanın tüm süreçleri yazar tarafından gerçekleştirilmiştir.

Çatışma beyanı: Yazar herhangi bir çıkar çatışması olmadığını beyan eder.

Destek ve teşekkür: Bu araştırmanın gerçekleştirilmesi için herhangi kişi ya da kurumdan fon desteği sağlanmamıştır.

\section{Kaynaklar}

Abdollahi, A. ve Abu Talib, M. (2015). Emotional intelligence moderates perfectionism and test anxiety among Iranian students. School Psychology International, 36(5), 498-512.

Adesokan, A. ve Eni-Olorunda, T. (2015). Emotional intelligence, academic procrastination and academic achievement in two tertiary institutions in South-Western Nigeria. Gender and Behaviour, 13(1), 6482-6487.

Ainley, J., Foreman, J. ve Sheret, M. (1991). High school factors that influence students to remain in school. The Journal of Educational Research, 85(2), 69-80.

Antony, M. M. ve Swinson, R. P. (1998). When perfect isn't good enough: Strategies for coping with perfectionism. Oakland, CA: New Harbinger Publications.

Argon, T. ve Kösterelioğlu, M. A. (2009). Üniversite öğrencilerinin üniversite yaşam kalitesi ve fakülte kültürüne ilişkin algıları. Elektronik Sosyal Bilimler Dergisi, 8(30), 43-61.

Baker, J. A., Dilly, L. J., Aupperlee, J. L. ve Patil, S. A. (2003). The developmental context of school satisfaction: Schools as psychologically healthy environments. School Psychology Quarterly, 18(2), 206-221.

Balk1s, M. (2013). Academic procrastination, academic life satisfaction and academic achievement: The mediation role of rational beliefs about studying. Journal of Cognitive \& Behavioral Psychotherapies, 13(1), 5774 .

Bar-On, R. (2006). The Bar-On Model Of Emotional-Social Intelligence (ESI). Psicothema, 18(Suplem.1), 13-25. 
Becker, M., McElvany, N. ve Kortenbruck, M. (2010). Intrinsic and extrinsic reading motivation as predictors of reading literacy: A longitudinal study. Journal of Educational Psychology, 102(4), 773-785.

Berber Çelik, Ç. ve Odacı, H. (2014). Akademik erteleme davranışının bazı kişisel ve psikolojik değişkenlere göre açıklanması. Hacettepe Üniversitesi Eğitim Fakültesi Dergisi, 30(3), 31-47.

Chow, H. P. (2011). Procrastination among undergraduate students: Effects of emotional intelligence, school life, self-evaluation, and self-efficacy. Alberta Journal of Educational Research, 57(2), 234-240.

Closson, L. M. ve Boutilier, R. R. (2017). Perfectionism, academic engagement, and procrastination among undergraduates: The moderating role of honors student status. Learning and Individual Differences, 57(July), $157-162$.

Constantin, K., English, M. M. ve Mazmanian, D. (2018). Anxiety, depression, and procrastination among students: rumination plays a larger mediating role than worry. Journal of Rational-Emotive $\mathcal{E}$ CognitiveBehavior Therapy, 36(1), 15-27.

Deniz, M. E., Özer, E. ve Işık, E. (2013). Duygusal Zekâ Özelliği Ölçeği-Kısa Formu: Geçerlik ve güvenirlik çalışması. Eğitim ve Bilim, 38(169), 407-419.

Deniz, M. E., Traş, Z. ve Aydoğan, D. (2009). An investigation of academic procrastination, locus of control, and emotional intelligence. Educational Sciences: Theory and Practice, 9(2), 607-632.

Dunn, R. ve Griggs, S. A. (2000). Practical Approaches to using Learning Styles in Higher Education. Bergin: Westport.

Duru, E. ve Balk1s, M. (2017). Procrastination, self-esteem, academic performance, and well-being: A moderated mediation model. International Journal of Educational Psychology, 6(2), 97-119.

Ferrari, J. R. ve Scher, S. J. (2000). Toward an understanding of academic and nonacademic tasks procrastinated by students: The use of daily logs. Psychology in the Schools, 37(4), 359-366.

Firestone, W. A., Rosenblum, S. ve Webb, A. (1987). Building commitment among students and teachers: An exploratory study of ten urban high schools. 20 Haziran 2019 tarihinde https://eric.ed.gov/?id=ED303535 erişildi.

Flett, G. L., Hewitt, P. L. ve Heisel, M. J. (2014). The destructiveness of perfectionism revisited: Implications for the assessment of suicide risk and the prevention of suicide. Review of General Psychology, 18(3), 156172.

Fraenkel, J. R. ve Wallen, N. E. (2011). How to design and evaluate research in education (8. ed.). New York: McGraw-Hill Education.

Frost, R. O., Marten, P., Lahart, C. ve Rosenblate, R. (1990). The dimensions of perfectionism. Cognitive Therapy and Research, 14(5), 449-468.

Garcia-Molsosa, M., Collet-Sabé, J., Martori, J. C. ve Montserrat, C. (2019). School satisfaction among youth in residential care: A multi-source analysis. Children and Youth Services Review, 105(October), 1-8.

Gaudreau, P., Franche, V. ve Gareau, A. (2016). A latent mediated moderation of perfectionism, motivation, and academic satisfaction: Advancing the $2 \times 2$ model of perfectionism through substantive-methodological synergy. Journal of Psychoeducational Assessment, 34(7), 688-701.

Goleman D. (1998). Working with emotional intelligence. Bantam Books: New York.

Goleman, D. (2006). Emotional intelligence. Bantam Books: New York.

Gong, X., Fletcher, K. L. ve Paulson, S. E. (2017). Perfectionism and emotional intelligence: A test of the $2 \times 2$ model of perfectionism. Personality and Individual Differences, 106(February), 71-76.

Güçlü, A. (2019). Ürküten rapor! 1.1 milyon öğrenci okulu bıraktı. 10 Temmuz 2019 tarihinde 
https://www.egitimajansi.com/haber/urkuten-rapor-11-milyon-ogrenci-okulu-birakti-haberi-68822h.html adresinden erişildi.

Hamachek, D. E. (1978). Psychodynamics of normal and neurotic perfectionism. Psychology: A Journal of Human Behavior, 15(1), 27-33.

Hammer, L. B., Grigsby, T. D. ve Woods, S. (1998). The conflicting demands of work, family, and school among students at an urban university. The Journal of Psychology, 132(2), 220-226.

Hayes, A. F. (2018). Introduction to mediation, moderation, and conditional process analysis: A regression-based approach. Guilford Publications: New York.

Huebner, E. S. (1994). Preliminary development and validation of a multidimensional life satisfaction scale for children. Psychological Assessment, 6(2), 149-158.

Kağan, M. (2009). Üniversite öğrencilerinde akademik erteleme davranışını açılayan değişkenlerin belirlenmesi. Ankara Üniversitesi Eğitim Bilimleri Fakültesi Dergisi, 42(2), 113-128.

Kamae, A. ve Weisani, M. (2014). The relationship between social anxiety irrational beliefs and emotional intelligence with homesickness in dormitory students of Tehran University. Indian Journal of Fundamental and Applied Science, 4(1), 285-292.

Karatzias, A., Power, K. G., Flemming, J., Lennan, F. ve Swanson, V. (2002). The role of demographics, personality variables and school stress on predicting school satisfaction/dissatisfaction: Review of the literature and research findings. Educational Psychology, 22(1), 33-50.

Kartol, A. (2013). Lise son sımı öğrencilerinin akılcı olmayan inançlarının çeşitli değgişkenler açısından incelenmesi (Yüksek lisans tezi). İnönü Üniversitesi, Malatya

Keser, G. ve Traş, Z. (2019). Üniversite öğrencilerinin akilci olmayan inanç empatik eğilim ve duygusal zeka düzeyleri arasindaki ilişkinin incelenmesi. MANAS Sosyal Araştırmalar Dergisi, 8(3), 2360-2380.

Matthews, G., Zeidner, M. ve Roberts, R. D. (2004). Emotional intelligence: Science and myth. Cambridge: MIT Press.

Odacı, H., Kalkan, M. ve Çikrıkci, Ö. (2017). Akademik Mükemmeliyetçilik Ölçeğinin geliştirilmesi]. Ahi Evran Üniversitesi Kırşehir Ĕ̆itim Fakültesi Dergisi, 18(1), 353-366.

Özdemir, M. (2012). Üniversite öğrencilerinin okul yaşamının niteliğine ilişkin algılarının cinsiyet ve fakülte değişkenlerine göre incelenmesi. Kuram ve Uygulamada Eğitim Yönetimi, 2(2), 225-242.

Özdemir, S., Kılınç, A. Ç., Öğdem, Z. ve Er, E. (2013). Eğitim fakültesi öğrencilerinin fakülte yaşamının niteliğine ilişkin memnuniyet düzeylerinin çeşitli değişkenler açısından incelenmesi. Yüksekögretim ve Bilim Dergisi, 3(3), 228-235.

Patch, A. R. (1984). Reflections on perfection. American Psychologist, 39(4), 386-390.

Petrides, K. V. ve Furnham, A. (2000). On the dimensional structure of emotional intelligence. Personality and Individual Differences, 29(2), 313-320.

Petrides, K. V. ve Furnham, A. (2001). Trait emotional intelligence: Psychometric investigation with reference to established trait taxonomies. European Journal of Personality, 15(6), 425-448.

Petrides, K. V., Gómez, M. G. ve Pérez-González, J. C. (2017). Pathways into psychopathology: Modeling the effects of trait emotional intelligence, mindfulness, and irrational beliefs in a clinical sample. Clinical Psychology \& Psychotherapy, 24(5), 1130-1141.

Preacher, K. J. ve Hayes, A. F. (2008). Asymptotic and resampling strategies for assessing and comparing indirect effects in multiple mediator models. Behavior Research Methods, 40(3), 879-891.

Ram, A. (2005). The relationship of positive and negative perfectionism to academic achievement, achievement 
Üniversite Öğrencilerinde Duygusal Zekâ ile ...

motivation, and well-being in tertiary students (Yüksek lisans tezi). University of Canterbury, Christchurch.

Randolph, J. J., Kangas, M. ve Ruokamo, H. (2009). The preliminary development of the Children's Overall Satisfaction with Schooling Scale (COSSS). Child Indicators Research, 2(1), 79-93.

Rego, A. ve Fernandes, C. (2004). Emotional intelligence and students' academic achievement. International Journal of Psychology, 39(5-6), 94.

Rice, K. G., Ashby, J. S. ve Slaney, R. B. (2007). Perfectionism and the five-factor model of personality. Assessment, 14(4), 385-398.

Rice, K. G., Richardson, C. M. ve Ray, M. E. (2016). Perfectionism in academic settings. F. M. Sirois ve D. S. Molnar (Ed.), Perfectionism, health, and well-being (ss. 245-264) içinde. Springer, Cham.

Salovey, P. veMayer, J. D. (1990). Emotional intelligence. Imagination, Cognition and Personality, 9(3), 185-211.

Semb, G., Glick, D. M. ve Spencer, R. E. (1979). Student withdrawals and delayed work patterns in self-paced psychology courses. Teaching of Psychology, 6(1), 23-25.

Sherry, S. B., Hewitt, P. L., Flett, G. L. ve Harvey, M. (2003). Perfectionism dimensions, perfectionistic attitudes, dependent attitudes, and depression in psychiatric patients and university students. Journal of Counseling Psychology, 50(3), 373-386.

Smith, M. M., Saklofske, D. H. ve Yan, G. (2015). Perfectionism, trait emotional intelligence, and psychological outcomes. Personality and Individual Differences, 85(October), 155-158.

Solomon, L. J. ve Rothblum, E. D. (1984). Academic procrastination: Frequency and cognitive-behavioral correlates. Journal of Counseling Psychology, 31(4), 503-509.

Steel, P. (2007). The nature of procrastination: A meta-analytic and theoretical review of quintessential selfregulatory failure. Psychological Bulletin, 133(1), 65-94.

Stein, S. J. (2009). Emotional intelligence for dummies. John Wiley \& Sons.

Suldo, S. M., Bateman, L. ve Gelly, C. D. (2014). Understanding and promoting school satisfaction in adolescence. M. J. Furlong, R. Gilman ve E. S. Huebner (Ed.), Handbook of positive psychology in schools (2. bs., ss. 365-380) içinde. New York: Routledge.

Telef, B. (2014). Turkish adaptation study of Overall School Satisfaction Scale for children. Journal of Theory and Practice in Education, 10(2), 478-490.

Thomas, E. H. ve Galambos, N. (2004). What satisfies students? Mining student-opinion data with regression and decision tree analysis. Research in Higher Education, 45(3), 251-269.

Tuckman, B. W. (1991). The development and concurrent validity of the procrastination scale. Educational and Psychological Measurement, 51(2), 473-480.

Uzun-Özer, B. Saçkes, M. ve Tuckman, B. W. (2013). Psychometric properties of the Tuckman Procrastination Scale in a Turkish sample. Psychological Reports, 113(3), 874-884.

Varaşteanu, C. M. ve Iftime, A. (2013). The role of the self-esteem, emotional intelligence, performance triad in obtaining school satisfaction. Procedia-Social and Behavioral Sciences, 93(21), 1830-1834.

Wolters, C. A., Shirley, L. Y. ve Pintrich, P. R. (1996). The relation between goal orientation and students' motivational beliefs and self-regulated learning. Learning and Individual Differences, 8(3), 211-238. 


\section{EXTENDED ABSTRACT}

\section{Introduction}

University, which is considered as the last phase of education in general, may be an important determiner of the work, family and social lives of students. Following a successful and qualified university education, individuals may feel adequate to perform their responsibilities when they start adult life. In this context, it is considered important to learn the perceptions of students on the quality of school life.

Although school satisfaction was previously investigated with primary, secondary and high school students, very little research was detected in the literature on the satisfaction of university students (GarciaMolsosa, Collet-Sabe, Martori, \& Montserrat, 2019; Thomas \& Galambos, 2004). School satisfaction includes the cognitive assessments of the individual about school performance including educational process and academic experiences and the relations with friends and teachers at school (Suldo, Baterman, \& Gelly, 2014). School satisfaction is considered as an important indicator of educational and emotional adjustment (Baker, Dilly, Aupperlee, \& Patil, 2003). In this way, the emotional intelligence concept (Goleman, 1998), which covers several competences including self-awareness, self-management skills, social awareness and relationship management, appears before us as a necessary factor in terms of the components of school satisfaction.

One of the factors that can be considered about academic processes between emotional intelligence and school satisfaction is the academic perfectionism concept. Perfectionism, which is defined as the desire to achieve the best (Flett, Hewitt, \& Heisel, 2014), includes positive (high performance, etc.) and negative (extreme stress, self-criticism, etc.) tendencies (Hamachek, 1978) depending on the individual. The struggle to make everything perfect brings with it difficulties for the individual to start and complete a job (Steel, 2007). For this reason, individuals who have academic perfectionism tend to show procrastination behaviors in terms of assignments, projects and presentations (Closson \& Boutilier, 2017). For this reason, academic procrastination was considered as another concept considered to have a mediator role between academic perfectionism and emotional intelligence and school satisfaction in the present study. As a result, it was foreseen that lowering academic perfectionism and academic procrastination levels would contribute positively to school satisfaction. For this reason, the responses to the following research questions were sought based on the theoretical explanations and previous study results mentioned in the literature.

1. Does academic perfectionism mediate between emotional intelligence and school satisfaction?

2. Does academic procrastination mediate between emotional intelligence and school satisfaction?

3. Are academic perfection and academic procrastination a serial mediator in the relationship between emotional intelligence and school satisfaction?

\section{Method}

This study was conducted with the participation of 309 university students, of whom $182(58.9 \%)$ were female and $127(41.1 \%)$ were male. Average daily working hour of the participants was $1.24(\mathrm{SD}=.98)$. Trait Emotional Intelligence Questionnaire-Short Form, the Academic Perfectionism Scale, the Tuckman Procrastination Scale, and the Overall Satisfaction with Schooling Scale, and Anxiety Scale were used as measurement instruments. The PROCESS v3.2 Macro, which was developed by Hayes (2018), was employed to test the serial/sequential multiple mediation of the academic perfectionism and academic procrastination between emotional intelligence and school satisfaction. Prior to the mediation model, the average, standard deviation, skewness and kurtosis coefficients of the variables were examined as preliminary analyzes. In addition to these, the Pearson Correlation Coefficient was employed to examine the relations between the variables.

\section{Results}

School satisfaction was positively correlated with emotional intelligence $(r=.58, p<.001)$ and negatively correlated with academic perfectionism $(r=-.47, p<.001)$ and academic procrastination $(r=-.50, p<.001)$. Also, there were a significant and negative association between emotional intelligence and academic perfectionism 
$(r=-.35, p<.001)$ and procrastination $(r=-.46, p<.001)$. Lastly, academic perfectionism and academic procrastination are positively related to each other, $(r=.32, p<.001)$.

In the first indirect effect, it was determined that emotional intelligence affected school satisfaction through academic perfectionism, (bootstrap $=.022,95 \% \mathrm{CI}=.012, .036$ ). Secondly, it was also determined that emotional intelligence predicted school satisfaction via academic procrastination, and that the indirect effect was also significant, (bootstrap $=.024,95 \% \mathrm{CI}=.013, .036$ ). Finally, it was understood that emotional intelligence affected school satisfaction at a significant level through academic perfectionism and academic procrastination, (bootstrap $=.004,95 \% \mathrm{CI}=.002, .007$ ). In addition to these, the mediation model, which was established to predict the school satisfaction, was significant; and three variables explained $47 \%$ of the total variance of school satisfaction.

\section{Conclusion}

The purpose of the present study was to examine the serial mediation roles of academic perfectionism and academic procrastination in the relation between emotional intelligence and school satisfaction in university students. According to the results of the analyses that were made in this respect, it was determined that academic perfectionism and academic procrastination had partial and serial mediation roles between these two variables. In other words, it was shown that the increase in the emotional intelligence scores of students might decrease their academic perfectionism and academic procrastination levels; and this indirect effect, in return, might increase school satisfaction. However, it was also determined that school satisfaction might increase directly with the increase in emotional intelligence.

The findings that was determined in the present study showing that emotional intelligence may be improved and academic perfectionism and academic procrastination variables may be reduced were also reported in previous studies. For this reason, it is recommended that psychological counselors conduct group counseling sessions on emotional intelligence, academic perfectionism and procrastination, which have significant effects on school satisfaction. For this reason, the emotional intelligence levels of students might increase, and in this way, the academic perfectionism and academic procrastination levels will decrease and the satisfaction of the school will increase. 